\title{
Fluxo gênico em soja geneticamente modificada e método para sua detecção
}

\author{
Welison Andrade Pereira ${ }^{(1)}$, Marcos Paiva Del Giúdice ${ }^{(1)}$, José Eustáquio de Souza Carneiro(1), \\ Denise Cunha Fernandes dos Santos Dias ${ }^{(1)}$ e Aluízio Borém ${ }^{(1)}$
}

\begin{abstract}
(1)Universidade Federal de Viçosa, Centro de Ciências Agrárias, Dep. de Fitotecnia, Av. P.H. Rolfs, s/no, CEP 36570-000 Viçosa, MG. E-mail: welisonaper@yahoo.com.br, mgiudice@ufv.br, jesc@ufv.br, dcdias@ufv.br, borem@ufv.br
\end{abstract}

\begin{abstract}
Resumo - O objetivo deste trabalho foi avaliar métodos para detecção de sementes de soja tolerante ao glifosato e o fluxo gênico de uma cultivar transgênica para uma convencional, em Florestal e Viçosa, MG. Para adequar método de detecção, foi conduzido experimento comparativo entre cinco bioensaios, dos quais se destacou o teste de germinação em substrato umedecido com solução do glifosato. $\mathrm{O}$ experimento de fluxo gênico foi instalado em campo, no esquema de quadrados concêntricos. No centro, foi plantada a cultivar tolerante ao glifosato (fonte de pólen). À sua volta, foi semeada a cultivar sensível (receptora do pólen). No estádio R8, foram colhidas sementes das laterais dos quadrados, em distâncias variadas da fonte de pólen: 0,5, 1, 2, 4 e 8 m. Amostras de 900 sementes, por fileira, foram avaliadas pelo teste de germinação em substrato umedecido com solução de glifosato a 0,06\%. Plântulas tolerantes ao glifosato indicaram fecundação cruzada. As maiores porcentagens de hibridação - 1,27\% em Florestal e 0,25\% em Viçosa-ocorreram a 0,5 m de distância, entre fonte e receptor de pólen, e essas taxas aproximaram-se de zero às distâncias de 2,26 e 1,16 m, para Florestal e Viçosa, respectivamente.
\end{abstract}

Termos para indexação: Glycine max, polinização cruzada, organismo geneticamente modificado.

\section{Gene flow in genetically modified soybean and method for its detection}

\begin{abstract}
The objective of this work was to assess the methods for detection of glyphosate tolerance soybean seeds and the gene flow from a genetically modified soybean cultivar to a conventional one, in Viçosa and Florestal, MG, Brazil. In order to assess the method for detection, a comparative experiment was conduct among five bioassays, from which the germination test in moistened substrate with glyphosate solution was outstanding. The experiment of gene flow was installed in field, in the concentric squares design. In the center, the glyphosatetolerant cultivar (pollen source) was planted. Around it, the sensitive cultivar (pollen receptor) was sowed. In the stage R8, seeds of lateral of the squares were harvested, in various distances from the pollen source: $0.5,1,2,4$ and $8 \mathrm{~m}$. Samples of 900 seeds by row were evaluated, using the germination test in moistened substrate with a solution of glyphosate at $0.06 \%$. Glyphosate-tolerant seedlings indicated cross-pollination. The largest hybridization rates $-1.27 \%$ in Florestal, and $0.25 \%$ in Viçosa - ocurred at $0.5 \mathrm{~m}$ distance between source and pollen receiver, and these rates reached zero at 2.26 and $1.16 \mathrm{~m}$ distances, in Florestal and Viçosa, respectively.
\end{abstract}

Index terms: Glycine max, cross-pollination, genetically modified organism.

\section{Introdução}

O Brasil é o segundo maior produtor mundial de soja; sua safra 2005/2006 ultrapassou 53,4 milhões de toneladas de grãos (Conab, 2006). O País também se destaca ao ocupar a terceira colocação, no mundo, em área plantada com transgênicos, que chega aos 9,4 milhões de hectares cultivados com soja geneticamente modificada (James, 2005).

$\mathrm{O}$ advento da soja Roundup Ready (RR), variedade geneticamente modificada tolerante ao herbicida glifosato, gerou várias expectativas, favoráveis à sua adoção, sobre: a redução no uso de herbicidas; a facilidade para a adoção do plantio direto; a flexibilidade de aplicação do herbicida só no tempo e local necessários; e o menor impacto ambiental (Kleba, 1998). Além disso, o manejo das lavouras é favorecido, as perdas de produção reduzidas (Siqueira et al., 2004) e, com isso, o aumento na produtividade e estabilidade das lavouras é potencial. Todos estes aspectos constituem benefícios relevantes para a cultura da soja geneticamente modificada; entretanto, questiona-se a 
existência de riscos ambientais, e entre os principais está o de escape gênico.

Os herbicidas inibidores da enzima EPSPS (5-enolpiruvilshiquimato 3 -fosfato sintase) são classificados como sistêmicos, pós-emergentes, não seletivos, que controlam plantas mono e dicotiledôneas, anuais e perenes (Shah et al., 1986; Kruse et al., 2000; Amarante Júnior et al., 2002a, 2002b). A soja geneticamente modificada, tolerante ao glifosato, apresenta expressão dupla da enzima EPSPS, uma que é original desta espécie, e outra proveniente do transgene CP4 EPSPS, que é tolerante ao herbicida inibidor da EPSPS (Kleba, 1998). O gene codificador dessa enzima é monogênico dominante (Padgette et al., 1995) e pode ser usado, como marcador morfológico de fecundação cruzada, entre duas variedades puras e contrastantes.

A possibilidade de ocorrência de fluxo gênico, de uma variedade geneticamente modificada para uma convencional, e a possibilidade de se detectarem sementes de soja tolerante ao glifosato em mistura com soja convencional, são assuntos relevantes com a chegada e expansão do cultivo de organismos geneticamente modificados. Em plena globalização econômica e expansão da adoção da transgenia na agricultura, a diversidade de mercado exige variedade de produtos e que estes sejam precisamente identificados para a comercialização. Existem variados nichos comerciais no agronegócio, e a necessidade de meios que detectem as principais características de uma determinada cultivar se faz imperativa, tanto para a produção de sementes com pureza genética garantida, quanto para a certificação de produtos.

Vários métodos, com capacidade comprovada de identificar a tolerância e sensibilidade ao glifosato, têm sido publicados na literatura. Os bioensaios não exigem mão-de-obra altamente especializada nem equipamentos sofisticados e, além disso, geram resultados que variam de 3 a 14 dias após a implantação do teste (Bevilaqua et al., 2000; Torres et al., 2003; Funguetto et al., 2004; Menezes et al., 2004; Tillmann \& West, 2004; Cunha et al., 2005; Miranda et al., 2005). Esses testes se baseiam no fato de que a ocorrência do gene CP4 EPSPS possibilita aos genótipos tolerância ao glifosato.

O objetivo deste trabalho foi avaliar métodos para detecção de sementes de soja tolerante ao glifosato e o fluxo gênico de uma cultivar de soja transgênica para uma convencional, em Florestal e Viçosa, MG.

\section{Material e Métodos}

Bioensaios para detecção de sementes de soja geneticamente modificada tolerante ao glifosato

Os bioensaios foram conduzidos no laboratório de sementes e nas casas de vegetação do Departamento de Fitotecnia, da Universidade Federal de Viçosa, nos meses de junho e julho de 2005.

As cultivares utilizadas foram CD219RR (Coodetec - Cooperativa Central de Pesquisa Agrícola), tolerante ao glifosato, e Elite (Coopadap - Cooperativa Agropecuária Alto Paranaíba), sensível a este herbicida. As cultivares foram escolhidas por apresentar, entre outros materiais disponíveis, boa qualidade fisiológica. Amostras das sementes foram submetidas ao teste de germinação (Brasil, 1992), em que se observaram médias acima de $90 \%$.

Utilizou-se o herbicida comercial Roundup, que possui formulação de $480 \mathrm{~g} \mathrm{~L}^{-1}$ do ingrediente ativo sal de isopropilamina de $\mathrm{n}$-(fosfometil) glicina e $360 \mathrm{~g} \mathrm{~L}^{-1} \mathrm{de}$ equivalente ácido de $\mathrm{N}$-(fosfonometil) glicina. Para os ajustes de concentrações e preparo das soluções, bem como para embebição das sementes, foi utilizada água destilada. Os rolos de papel com as sementes foram mantidos em câmara de germinação $\left(25 \pm 1^{\circ} \mathrm{C}\right)$.

No primeiro bioensaio, as sementes das cultivares CD219RR e Elite foram submetidas a cinco tratamentos: sementes sem tratamento prévio (controle negativo); sementes submersas em água, por uma hora (controle positivo); sementes submetidas, por uma hora, às concentrações $0,03,0,06$ e $0,12 \%$ do equivalente ácido (e.a.) do herbicida.

Após o período de imersão, as sementes foram lavadas em água corrente (Funguetto et al., 2004) e distribuídas, manualmente, em leito de areia previamente esterilizada e acomodada em bandejas de plástico. Em cada bandeja (40x27x5 cm), foram distribuídas 150 sementes, dispostas em 6 sulcos de $2 \mathrm{~cm}$ de profundidade $(25$ sementes por sulco). Assim, em cada bandeja foram semeados de 1 a 3 tratamentos distintos, conforme a casualização. $\mathrm{O}$ delineamento experimental foi inteiramente casualizado, em esquema fatorial $2 \times 5$ ( 2 cultivares $\times 5$ tratamentos), com 4 repetições de 50 sementes.

No segundo bioensaio, as sementes das duas cultivares foram submersas, por uma hora, nas soluções: 0, 0,03, 0,06 e $0,12 \%$ do e.a. do glifosato. Em seguida, foram transferidas para papel germiteste umedecido com água destilada (2,5 x peso do substrato seco). O delineamento 
experimental foi inteiramente casualizado, em esquema fatorial $2 \times 4$ ( 2 cultivares $\times 4$ tratamentos), com 4 repetições de 50 sementes.

No terceiro bioensaio, as sementes foram germinadas em substrato umedecido com as soluções a $0,0,03,0,06$ e $0,12 \%$ do e.a. do glifosato, em delineamento experimental inteiramente casualizado, em esquema fatorial $2 \times 4$ (2 cultivares $\mathrm{x}$ 4 tratamentos), com 4 repetições de 50 sementes.

No quarto bioensaio, as sementes foram pré-embebidas em papel umedecido com as soluções a $0,0,3,0,6$ e 1,2\% do e.a. do glifosato, por 24 horas. Após esse período, as sementes foram germinadas em substrato umedecido com água destilada $(2,5 \mathrm{x}$ peso do substrato seco). $\mathrm{O}$ delineamento experimental foi inteiramente casualizado, em esquema fatorial $2 \times 4$ ( 2 cultivares $\mathrm{x} 4$ tratamentos), com 4 repetições de 50 sementes.

No quinto bioensaio, foram adicionadas à cada caixa gerbox oito unidades de papel filtro, umedecidas com as soluções a de $0,0,18,0,36$ e $0,54 \%$ do e.a. do glifosato. As caixas, com 25 sementes cada, foram mantidas em temperatura ambiente durante 7 dias. Foi adotado o delineamento experimental inteiramente casualizado, em esquema fatorial $2 \times 4$ ( 2 cultivares $\mathrm{x}$ 4 tratamentos), com 8 repetições de 25 sementes.

No primeiro bioensaio, foram analisados, ao sétimo dia: a porcentagem de emergência (considerada plântula emergida aquela com o cotilédone já emitido, em ângulo igual ou superior a $90^{\circ}$, acima do nível da areia), índice de velocidade de emergência (IVE) (Nakagawa, 1994), comprimento médio em centímetros do hipocótilo e da raiz primária, porcentagem de plântulas normais e anormais (Brasil, 1992). No segundo, terceiro e quarto bioensaios, foram avaliados, ao sétimo dia: comprimento médio de plântulas, porcentagem de plântulas normais e anormais e a porcentagem de plântulas dotadas de raízes secundárias. No quinto bioensaio, foram avaliados, ao sétimo dia: emissão de raiz primária, emissão de raízes secundárias e número de sementes não germinadas, com todos os valores expressados em porcentagem.

Todos os dados em porcentagem foram transformados em arc sen $(\mathrm{x} / 100)^{0,5}$. Contudo, para melhor visualização, os resultados foram apresentados, graficamente, em seus valores originais de porcentagem. As médias foram comparadas pelo teste de Tukey, a $5 \%$ de probabilidade. Para as análises estatísticas, foi utilizado o Sistema de Análises Estatísticas e Genéticas da UFV (SAEG-UFV, 1993).

Os bioensaios foram comparados por sua eficiência em diferenciar plântulas tolerantes das sensíveis ao herbicida e quanto à sua praticidade na implantação.

\section{Análise do fluxo gênico em soja geneticamente modificada tolerante ao glifosato}

As variedades utilizadas neste estudo foram CD219RR, tolerante ao glifosato, e CD211, convencional, sensível. Ambas concedidas pela Coodetec e escolhidas por apresentarem o mesmo ciclo e padrão de florescimento.

Os experimentos foram implantados no campo experimental da Agronomia, da Universidade Federal de Viçosa, em Viçosa, MG $\left(20^{\circ} 45^{\prime} \mathrm{S}, 42^{\circ} 52^{\prime} \mathrm{W}\right.$, altitude $648 \mathrm{~m}$ ); e no campo experimental da Central de Ensino e Desenvolvimento Agrário de Florestal (Cedaf), em Florestal, MG (19 $52^{\circ} \mathrm{S}, 44^{\circ} 25^{\prime} \mathrm{W}$, altitude $\left.749 \mathrm{~m}\right)$.

Todos os procedimentos adotados na implantação e condução dos ensaios foram os mesmos nas duas localidades. Os experimentos foram instalados no mês de dezembro de 2004, e a colheita foi realizada em abril de 2005. Nesse período, a temperatura média em Florestal foi de $23,4^{\circ} \mathrm{C}$ e em Viçosa foi de $23^{\circ} \mathrm{C}$ (Simge, 2005).

$\mathrm{O}$ experimento foi instalado em esquema de quadrados concêntricos espaçados em $0,5 \mathrm{~m}$. A partir do primeiro quadrado, central, com $0,5 \mathrm{~m}$ de lado, os demais foram estabelecidos até se chegar ao último, no total de $22,5 \mathrm{~m}$ de lateral. Para evitar que as sementes fossem plantadas em fileiras impróprias, primeiro foi semeada a cultivar tolerante ao glifosato, no centro e, depois, ao redor, a cultivar sensível.

As práticas culturais seguiram as recomendações para a soja em Minas Gerais. Não foi aplicado inseticida próximo à época de florescimento nem durante este período.

No estádio R8, foram colhidas as sementes das fileiras correspondentes às laterais dos quadrados da cultivar CD211, em diferentes distâncias da fonte de pólen (CD219RR): 0,5, 1, 2, 4 e 8 m, tendo sido estes considerados os tratamentos. Cada lado do quadrado foi colhido separadamente, como uma repetição do tratamento (fileira). Assim, cada distância possuiu quatro repetições. Colheita e trilhagem foram realizadas individualmente, em

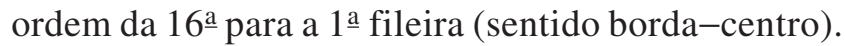

O tamanho de cada amostra (n) de sementes a ser analisada foi obtido a partir da equação: $\mathrm{n}=[\log (1-\mathrm{P})] /[\log (1-\mathrm{p})]$; em que $\mathrm{n}$ é o número de 
sementes da amostra; P é a probabilidade de o evento não ocorrer em razão do acaso; e p é a taxa, em decimal, da fecundação cruzada esperada (Ramalho et al., 2000).

A taxa de fecundação cruzada em soja, em condições de campo, varia de 0 a 2,43\% (Jones \& Hayes, 1916; Woodworth, 1922; Garber \& Odland, 1926; Cutler, 1934; Miyasaka, 1958; Probst, 1961; Caviness, 1966; Sediyama, 1970; Vernetti et al., 1972; Abud et al., 2003; Ray et al., 2003). Para este trabalho, avaliou-se a probabilidade (p) de fecundação cruzada esperada de $0,51 \%$ (valor obtido da média dos resultados encontrados nos trabalhos sobre fecundação cruzada natural). Assim, com $\mathrm{P}=0,99 \mathrm{e}$ $\mathrm{p}=0,51$, o n encontrado foi de 900 sementes por amostra.

Para avaliar a ocorrência de fecundação cruzada, as sementes foram germinadas em papel germiteste umedecido com solução $0,06 \%$ de glifosato $(2,5$ x peso de substrato seco), identificado entre os bioensaios para detecção de soja geneticamente modificada como o método mais adequado. As amostras dos tratamentos foram analisadas sete dias após a implantação do teste. As 900 sementes foram distribuídas em 18 rolos de papel germiteste com 50 sementes cada.

Os dados foram submetidos à análise de regressão linear com platô, escolhida por ser a regressão que melhor explicou os resultados. Para cada localidade, as equações de regressão foram ajustadas, tendo-se utilizado as médias das quatro repetições de cada tratamento.

\section{Resultados e Discussão}

No primeiro bioensaio para detecção de sementes de soja geneticamente modificada, observou-se que para a característica índice de velocidade de emergência (IVE), houve diferenças entre as cultivares, nos tratamentos com 0,06 e $0,12 \%$ do equivalente ácido (e.a.) do glifosato
(Tabela 1). Contudo, esta característica não foi marcante na distinção, em razão de seu efeito negativo também na variedade tolerante ao herbicida.

Com relação à porcentagem de emergência, houve inibição da emergência das plântulas da cultivar sensível, a partir da concentração $0,03 \%$ do e.a. do glifosato (Tabela 1).

Segundo Bevilaqua et al. (2000), Torres et al. (2003) e Tillmann \& West (2004), em presença do glifosato, embriões de cultivares sensíveis iniciam o processo germinativo, mas logo paralisam o seu desenvolvimento, fato também observado neste trabalho.

Observou-se redução no comprimento da raiz primária das plântulas da cultivar sensível, nos tratamentos com glifosato, enquanto para a cultivar tolerante não houve diferença significativa entre os tratamentos. Essa característica é adequada para diferenciar as variedades, em relação à tolerância ao herbicida, conforme também observado por Goggi \& Stahr (1997), Bevilaqua et al. (2000), Funguetto el al. (2004) e Tillmann \& West (2004).

O hipocótilo se tornou reduzido e pouco desenvolvido na variedade sensível, em presença do herbicida. A redução observada para o comprimento do hipocótilo foi menos acentuada do que para o comprimento de raiz primária. Resultados semelhantes foram relatados por Goggi \& Stahr (1997), Bevilaqua et al. (2000), Funguetto et al. (2004) e Tillmann \& West (2004).

Em presença do glifosato, houve diferença entre as cultivares quanto às características plântulas normais e anormais, assim como verificado por Bevilaqua et al. (2000). A partir do tratamento a $0,03 \%$ do e.a. do herbicida, foram observados: queda na porcentagem de plântulas normais e aumento proporcional de plântulas anormais, na variedade sensível.

A concentração do herbicida de $0,03 \%$ do e.a. mostrou-se apropriada para a caracterização das

Tabela 1. Índice de velocidade de emergência (IVE), emergência, comprimento da raiz primária, comprimento do hipocótilo, plântulas normais e plântulas anormais das sementes das cultivares de soja Elite e CD219RR, submetidas por uma hora a diferentes concentrações de glifosato, no bioensaio de emergência em leito de $\operatorname{areia}^{(1)}$.

\begin{tabular}{|c|c|c|c|c|c|c|c|c|c|c|c|c|}
\hline \multirow[t]{2}{*}{ Tratamento $^{(2)}$} & \multicolumn{2}{|c|}{$\begin{aligned} \text { IVE } \\
(\%)\end{aligned}$} & \multicolumn{2}{|c|}{$\begin{array}{l}\text { Emergência } \\
(\%)\end{array}$} & \multicolumn{2}{|c|}{$\begin{array}{c}\text { Comprimento } \\
\text { da raiz primária }(\mathrm{cm})\end{array}$} & \multicolumn{2}{|c|}{$\begin{array}{l}\text { Comprimento do } \\
\text { hipocótilo }(\mathrm{cm})\end{array}$} & \multicolumn{2}{|c|}{$\begin{array}{c}\text { Plântulas normais } \\
(\%)\end{array}$} & \multicolumn{2}{|c|}{$\begin{array}{c}\text { Plântulas anormais } \\
(\%)\end{array}$} \\
\hline & Elite & $\overline{\text { CD219RR }}$ & Elite & CD219RR & Elite & CD219RR & Elite & CD219RR & Elite & CD219RR & Elite & CD219RR \\
\hline Controle negativo & $10,7 \mathrm{Aa}$ & $10,1 \mathrm{Aa}$ & $95,5 \mathrm{Aa}$ & $98,0 \mathrm{Aa}$ & $15 \mathrm{Aa}$ & $14,9 \mathrm{Aa}$ & $5,5 \mathrm{Aa}$ & $5,2 \mathrm{Aa}$ & $97,8 \mathrm{Aa}$ & $98,9 \mathrm{Aa}$ & $2,13 \mathrm{Ba}$ & $1,02 \mathrm{Ca}$ \\
\hline Controle positivo & $9,9 \mathrm{ABa}$ & $10,0 \mathrm{Aa}$ & $91,5 \mathrm{Aa}$ & $93,0 \mathrm{ABa}$ & $12 \mathrm{Aa}$ & $11,4 \mathrm{Aa}$ & $5,1 \mathrm{Aa}$ & $4,5 \mathrm{ABa}$ & $97,8 \mathrm{Aa}$ & $95,6 \mathrm{ABa}$ & $2,15 \mathrm{Ba}$ & $4,3 \mathrm{BCa}$ \\
\hline $0,03 \%$ & 7,7BCa & $8,9 \mathrm{ABa}$ & $75,5 \mathrm{Bb}$ & $85,0 \mathrm{BCa}$ & $3,1 \mathrm{Bb}$ & $13,3 \mathrm{Aa}$ & $2,1 \mathrm{Bb}$ & $3,9 \mathrm{Ba}$ & $14,7 \mathrm{Bb}$ & $95,2 \mathrm{ABa}$ & $85,2 \mathrm{Aa}$ & $4,7 \mathrm{BCb}$ \\
\hline $0,06 \%$ & $5,7 \mathrm{CDb}$ & $7,8 \mathrm{ABa}$ & $67,0 \mathrm{Bb}$ & $81,0 \mathrm{Ca}$ & $2,7 \mathrm{Bb}$ & $10,2 \mathrm{Aa}$ & $1,5 \mathrm{Bb}$ & $4,3 \mathrm{ABa}$ & $8,5 \mathrm{Bb}$ & $89,4 \mathrm{BCa}$ & $91,1 \mathrm{Aa}$ & $10,5 \mathrm{ABb}$ \\
\hline $0,12 \%$ & $4,4 \mathrm{Db}$ & $7,3 \mathrm{Ba}$ & $53,0 \mathrm{Cb}$ & $77,0 \mathrm{Ca}$ & $2,5 \mathrm{Bb}$ & $12,9 \mathrm{Aa}$ & $1,3 \mathrm{Bb}$ & $4,4 \mathrm{ABa}$ & $7,4 \mathrm{Bb}$ & $85,0 \mathrm{Ca}$ & $92,5 \mathrm{Aa}$ & $14,9 \mathrm{Ab}$ \\
\hline
\end{tabular}

(1) Médias seguidas por letras iguais, maiúsculas na coluna e minúsculas na linha, não diferem entre si pelo teste de Tukey, a $5 \%$ de probabilidade. ${ }^{(2)}$ Controle negativo: sementes sem tratamento prévio; controle positivo: sementes submersas em água por uma hora; $0,03,0,06$ e $0,12 \%$ : sementes submetidas às concentrações de $0,03,0,06$ e $0,12 \%$ do equivalente ácido do glifosato, por uma hora. 
variedades, na maioria das características estudadas, exceto para IVE, em que a dose de $0,06 \%$ do e.a. mostrou-se mais adequada.

Nos segundo, terceiro e quarto bioensaios, observou-se que o comprimento médio das plântulas (Tabela 2) foi uma das principais características, na distinção entre tolerância e sensibilidade ao glifosato (Funguetto et al., 2004; Tillmann $\&$ West, 2004; Cunha et al., 2005). Foi observado que, sob tratamento com herbicida, o comprimento médio de plântulas sensíveis diminuiu significativamente em relação ao controle, o que não ocorreu para a cultivar tolerante.

A porcentagem de plântulas normais mostrou-se característica fundamental na distinção das cultivares. A presença do glifosato não permitiu a formação de plântulas normais pela cultivar sensível, observação também relatada por Bevilaqua et al. (2000).

Como também verificado por outros autores (Torres et al., 2003; Funguetto et al., 2004; Tillmann \& West, 2004), em presença do herbicida, a cultivar tolerante apresentou plântulas com raízes secundárias em todos os tratamentos, ao contrário do que se observou para a cultivar sensível, que não emitiu essas raízes em presença do glifosato. No bioensaio 3, o desenvolvimento de raízes secundárias da cultivar tolerante não foi prejudicado, aspecto fundamental na caracterização destes genótipos (Tabela 2). Com a redução no comprimento das plântulas da cultivar sensível, em presença do herbicida, houve paralisação no desenvolvimento da raiz primária, e não houve emissão de raízes secundárias.
No teste de germinação em caixa gerbox, não foram observadas diferenças entre as cultivares quanto à emissão de raiz primária, o que indica que sensibilidade e tolerância ao glifosato são características que parecem não estar relacionadas a sua emissão (Tabela 3 ). Com base nos demais bioensaios, pode-se concluir que o herbicida afeta o comprimento da raiz primária, mas não a sua emissão.

Verificou-se diferença, entre as cultivares, quanto à emissão de raízes secundárias. Em presença do glifosato, mesmo na menor concentração, a emissão dessas raízes ocorreu somente nas plântulas da cultivar CD219RR. Resultados semelhantes foram observados em outros estudos (Torres et al., 2003; Funguetto et al., 2004; Tillmann \& West, 2004). Este resultado foi predominante em todos os bioensaios de germinação, tanto em papel como em caixa gerbox (Tabelas 2 e 3 ).

O número de sementes não germinadas, ao sétimo dia, não discriminou as cultivares em relação à presença ou ausência de tolerância ao glifosato.

Apesar de ter apresentado resultados positivos para a diferenciação das variedades, o teste de germinação em caixa gerbox não foi consistente, mas confirmou a inibição do desenvolvimento de raízes secundárias, pela variedade sensível, como marcador morfológico de sensibilidade ao glifosato.

Nos três bioensaios, em papel germiteste, foi possível identificar plântulas tolerantes e sensíveis ao glifosato. Considerando-se a eficiência similar na caracterização das plântulas, o bioensaio com o umedecimento do papel germiteste, com solução do

Tabela 2. Comprimento de plântulas, plântulas normais, plântulas anormais e plântulas com raízes secundárias, das sementes das cultivares de soja Elite e CD219RR, submetidas ao bioensaio de germinação após imersão em solução de glifosato, ao teste de germinação em substrato umedecido com solução de glifosato, e ao bioensaio de germinação após pré-embebição por 24 horas, em papel germiteste umedecido com solução de glifosato $^{(1)}$.

\begin{tabular}{|c|c|c|c|c|c|c|c|c|}
\hline \multirow[t]{2}{*}{ Tratamento $^{(2)}$} & \multicolumn{2}{|c|}{ Comprimento de plântulas $(\mathrm{cm})$} & \multicolumn{2}{|c|}{ Plântulas normais (\%) } & \multicolumn{2}{|c|}{ Plântulas anormais (\%) } & \multicolumn{2}{|c|}{ Plântulas com raízes secundárias (\%) } \\
\hline & Elite & CD219RR & Elite & CD219RR & Elite & CD219RR & Elite & CD219RR \\
\hline & \multicolumn{8}{|c|}{ Bioensaio de germinação após imersão em solução de glifosato } \\
\hline $0,00 \%$ & $18,9 \mathrm{Aa}$ & $18,4 \mathrm{Aa}$ & $74,0 \mathrm{Aa}$ & $82,5 \mathrm{Aa}$ & $17,5 \mathrm{Ba}$ & $15,0 \mathrm{Aa}$ & $93,0 \mathrm{Aa}$ & $97,0 \mathrm{Aa}$ \\
\hline $0,03 \%$ & $5,3 \mathrm{Bb}$ & $17,8 \mathrm{Aa}$ & $0,0 \mathrm{Bb}$ & $71,0 \mathrm{Aa}$ & $92,0 \mathrm{Ab}$ & $20,0 \mathrm{Aa}$ & $0,0 \mathrm{Bb}$ & $92,5 \mathrm{ABa}$ \\
\hline $0,06 \%$ & $4,8 \mathrm{Bb}$ & $19,5 \mathrm{Aa}$ & $0,0 \mathrm{Bb}$ & $70,0 \mathrm{Aa}$ & $87,0 \mathrm{Ab}$ & $20,5 \mathrm{Aa}$ & $0,0 \mathrm{Bb}$ & $91,5 \mathrm{ABa}$ \\
\hline $0,12 \%$ & $3,5 \mathrm{Bb}$ & $19,3 \mathrm{Aa}$ & $0,0 \mathrm{Bb}$ & $67,0 \mathrm{Aa}$ & $91,0 \mathrm{Ab}$ & $23,0 \mathrm{Aa}$ & $0,0 \mathrm{Bb}$ & $89,0 \mathrm{Ba}$ \\
\hline \multicolumn{9}{|c|}{ Bioensaio de germinação em substrato umedecido com solução de glifosato } \\
\hline $0,00 \%$ & $21,1 \mathrm{Ab}$ & $25,4 \mathrm{Aa}$ & $89,0 \mathrm{Aa}$ & $91,0 \mathrm{Aa}$ & $8,0 \mathrm{Ba}$ & $8,0 \mathrm{Ba}$ & $96,0 \mathrm{Aa}$ & $97,5 \mathrm{Aa}$ \\
\hline $0,03 \%$ & $4,2 \mathrm{Bb}$ & $20,3 \mathrm{Ba}$ & $0,0 \mathrm{Bb}$ & $91,0 \mathrm{Aa}$ & $91,0 \mathrm{Aa}$ & $7,0 \mathrm{Bb}$ & $0,0 \mathrm{Bb}$ & $98,0 \mathrm{Aa}$ \\
\hline $0,06 \%$ & $3,0 \mathrm{Bb}$ & $8,9 \mathrm{Ca}$ & $0,0 \mathrm{Bb}$ & $77,5 \mathrm{Ba}$ & $96,5 \mathrm{Aa}$ & $16,0 \mathrm{ABb}$ & $0,0 \mathrm{Bb}$ & $97,5 \mathrm{Aa}$ \\
\hline $0,12 \%$ & $2,2 \mathrm{Bb}$ & $4,8 \mathrm{Da}$ & $0,0 \mathrm{Bb}$ & $70,0 \mathrm{Ba}$ & $96,0 \mathrm{Aa}$ & $26,5 \mathrm{ABb}$ & $0,0 \mathrm{Bb}$ & $95,0 \mathrm{Aa}$ \\
\hline \multicolumn{9}{|c|}{ Bioensaio de germinação após pré-embebição por 24 horas em papel germiteste umedecido com solução de glifosato } \\
\hline $0,00 \%$ & $11,2 \mathrm{Ab}$ & $24,7 \mathrm{Aa}$ & $86,0 \mathrm{Aa}$ & $94,0 \mathrm{Aa}$ & $12,0 \mathrm{Ba}$ & $6,0 \mathrm{Bb}$ & $99,0 \mathrm{Aa}$ & $99,5 \mathrm{Aa}$ \\
\hline $0,30 \%$ & $3,3 \mathrm{Ab}$ & $14,2 \mathrm{Ba}$ & $0,0 \mathrm{Bb}$ & $81,0 \mathrm{Aa}$ & $96,5 \mathrm{Aa}$ & $14,5 \mathrm{Ab}$ & $0,0 \mathrm{Bb}$ & $96,0 \mathrm{Aa}$ \\
\hline $0,60 \%$ & $2,7 \mathrm{Ab}$ & $9,1 \mathrm{Ca}$ & $0,0 \mathrm{Bb}$ & $78,0 \mathrm{Aa}$ & $90,0 \mathrm{Aa}$ & $20,5 \mathrm{Ab}$ & $0,0 \mathrm{Bb}$ & $93,0 \mathrm{Aa}$ \\
\hline $1,20 \%$ & $2,7 \mathrm{Ab}$ & $7,0 \mathrm{Da}$ & $0,0 \mathrm{Bb}$ & $77,0 \mathrm{Aa}$ & $93,5 \mathrm{Aa}$ & $20,0 \mathrm{Ab}$ & $0,0 \mathrm{Bb}$ & $88,5 \mathrm{Ba}$ \\
\hline
\end{tabular}

(1)Para cada um dos bioensaios, médias seguidas por letras iguais, maiúsculas na coluna e minúsculas na linha, não diferem entre si pelo teste de Tukey, a $5 \%$ de probabilidade. ${ }^{(2)}$ Concentração do equivalente ácido do glifosato. 
herbicida, destacou-se dos demais, por ser mais prático e por fornecer melhor caracterização na inibição do desenvolvimento de raízes secundárias somente pela variedade sensível ao glifosato.

Quanto às concentrações das soluções, $0,03 \%$ de e.a. foi eficiente para caracterização das plântulas quanto à tolerância ao herbicida, resultado encontrado também por Funguetto et al. (2004). Contudo, para um trabalho de identificação de indivíduos tolerantes, entre sementes geradas por uma cultivar sensível, julgou-se que a concentração $0,06 \%$ do e.a. seria mais apropriada, para submeter as amostras, analisadas em teste de germinação, à condição de maior estresse, o que destacaria absolutamente plântulas tolerantes ao herbicida. Este protocolo surgiu da constatação de que, sob esta condição, nenhuma plântula sensível emitiu raízes secundárias e nem ultrapassou os $5 \mathrm{~cm}$ de comprimento total. Assim, plântula com comprimento superior a $5 \mathrm{~cm}$ e dotada de radícula e raízes secundárias desenvolvidas foi considerada normal (Cunha et al., 2005) e tolerante ao herbicida.

$\mathrm{Na}$ análise do fluxo gênico em soja geneticamente modificada, os porcentuais médios de taxas de fecundação cruzada diferiram para os dois locais e foram superiores em Florestal, MG. Com base nos resultados obtidos, é possível que a distância seja capaz de isolar, em campo, as variedades de soja, para prevenir o escape gênico (Tabela 4). Florestal está em altitude maior que Viçosa, e a temperatura média nesse Município $\left(23,4^{\circ} \mathrm{C}\right)$ foi superior à de Viçosa $\left(23^{\circ} \mathrm{C}\right)$. É possível que diferenças ambientais tenham interferido na ocorrência de fluxo gênico, já que os insetos que são os polinizadores naturais da soja são encontrados em maior abundância em temperaturas mais altas.

Tabela 3. Plântulas com emissão de raiz primária, plântulas com emissão de raízes secundárias, e sementes não germinadas, das sementes das cultivares Elite e CD219RR, submetidas ao teste de germinação em caixa gergox com substrato umedecido com solução de glifosato $^{(1)}$.

\begin{tabular}{|c|c|c|c|c|}
\hline \multirow[t]{2}{*}{ Tratamento $^{(2)}$} & \multicolumn{2}{|c|}{$\begin{array}{c}\text { Emissão de } \\
\text { raiz primária }(\%)\end{array}$} & $\begin{array}{c}\text { Emissão de raízes } \\
\text { secundárias }(\%)\end{array}$ & $\begin{array}{c}\text { Sementes não } \\
\text { germinadas }(\%)\end{array}$ \\
\hline & Elite & $\overline{\text { CD219RR }}$ & Elite CD219RR & Elite CD219RR \\
\hline $0,00 \%$ & $96 \mathrm{Aa}$ & $97,5 \mathrm{Aa}$ & $92,5 \mathrm{Aa} \quad 96,5 \mathrm{Aa}$ & $11,5 \mathrm{Ba}$ \\
\hline $0,18 \%$ & $94 \mathrm{ABa}$ & $94,0 \mathrm{ABa}$ & $0,0 \mathrm{Bb} \quad 90,5 \mathrm{Ba}$ & $11,5 \mathrm{Ba}$ \\
\hline $0,36 \%$ & $93 \mathrm{ABa}$ & $95,0 \mathrm{ABa}$ & $0,0 \mathrm{Bb} \quad 87,0 \mathrm{Ba}$ & $13,0 \mathrm{Ba} \quad 2,0 \mathrm{Ab}$ \\
\hline $0,54 \%$ & $91 \mathrm{Ba}$ & $91,5 \mathrm{Ba}$ & $0,0 \mathrm{Bb} \quad 56,0 \mathrm{Ca}$ & $20,5 \mathrm{Aa} \quad 2,0 \mathrm{Ab}$ \\
\hline
\end{tabular}

(1)Médias seguidas por letras iguais, maiúsculas na coluna e minúsculas na linha, não diferem entre si pelo teste de Tukey, a 5\% de probabilidade. ${ }^{(2)}$ Concentração do equivalente ácido do glifosato.
De forma similar ao verificado em alguns estudos (Boerma \& Moradshahi, 1975; Ahrent \& Caviness, 1994; Abud et al., 2003; Ray et al., 2003), aos 8 m de distância da fonte de pólen, não foram detectados eventos de fecundação cruzada em nenhuma das localidades. Aos $4 \mathrm{~m}$ de distância da fonte de pólen, observou-se a ocorrência de hibridação em Florestal, mas não em Viçosa. Abud et al. (2003) não observaram disseminação de pólen transgênico a partir dos 6,5 m. Outros autores também citaram ocorrência de fecundação cruzada aos $4 \mathrm{~m}$ de distância da fonte de pólen (Boerma \& Moradshahi, 1975; Ahrent \& Caviness, 1994; Ray et al., 2003).

$O$ fato de a fecundação cruzada ter ocorrido num local e não no outro, aos $4 \mathrm{~m}$ de distância da fonte, sugere que a fecundação cruzada foi influenciada pelo meio ambiente e que este é relevante para as taxas de fecundação cruzada, encontradas em outros trabalhos (Cutler, 1934; Caviness, 1966; Rubis, 1970; Sediyama et al., 1970; Ahrent \& Caviness, 1994; Abud et al., 2003).

À medida que a distância da variedade sensível para a variedade tolerante foi diminuindo, observouse aumento na taxa de fecundação cruzada. A $2 \mathrm{~m}$ de distância da fonte, nos dois locais, foram observados casos de hibridação. A $1 \mathrm{~m}$ de distância, as taxas de fecundação cruzada foram de $0,80 \mathrm{e}$ $0,08 \%$, em Florestal e Viçosa, respectivamente. Maiores taxas de fecundação cruzada foram observadas em Florestal do que em Viçosa, o que foi confirmado a $0,5 \mathrm{~m}$ de distância da fonte de pólen, onde foram observadas 1,27 e $0,80 \%$ de hibridação para Florestal e Viçosa, respectivamente.

Para as duas localidades, o maior número de eventos foi observado na menor distância entre doador e receptor de pólen, como constatado também por Caviness (1966), Abud et al. (2003) e Ray et al. (2003).

A análise de regressão linear com platô estimou, para as duas localidades, as distâncias até onde o efeito de polinização cruzada ocorreu (Figura 1). Para Florestal,

Tabela 4. Porcentagem média de fecundação cruzada, nas diferentes fileiras da cultivar sensível CD211RR.

\begin{tabular}{ccc}
\hline Fileira CD211 (distância da & \multicolumn{2}{c}{ Localidades } \\
\cline { 2 - 3 } fonte de pólen - CD219RR) & Viçosa & Florestal \\
\hline $1(0,5 \mathrm{~m})$ & 0,25 & 1,27 \\
$2(1 \mathrm{~m})$ & 0,08 & 0,80 \\
$4(2 \mathrm{~m})$ & 0,08 & 0,25 \\
$8(4 \mathrm{~m})$ & 0,00 & 0,33 \\
$16(8 \mathrm{~m})$ & 0,00 & 0,00 \\
\hline & $\mathrm{r}=-0,7276$ & $\mathrm{r}=-0,8053$ \\
\hline
\end{tabular}




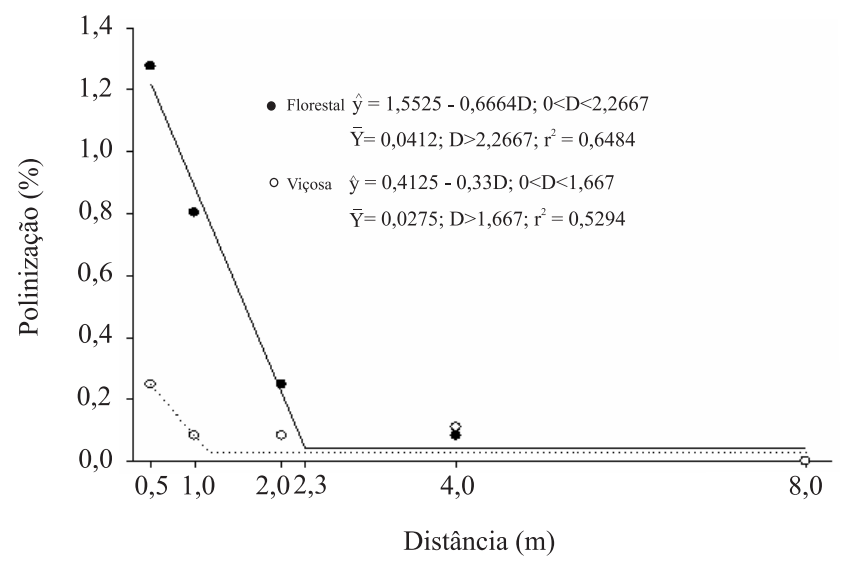

Figura 1. Regressão linear, com platô, dos dados de polinização cruzada obtidos para as localidades de Viçosa e Florestal. D: distância em metros.

a taxa de fecundação cruzada aproximou-se de zero, à distância de 2,27 $\mathrm{m}$ da fonte. A partir desse ponto, a taxa de hibridação natural teria se estabilizado em 0,0412\%. Para Viçosa, a distância encontrada foi de $1,17 \mathrm{~m}$, a partir da qual a taxa de hibridação natural seria de $0,0275 \%$, isto é, praticamente zero.

\section{Conclusões}

1. O bioensaio de germinação, em papel germiteste umedecido com solução do herbicida à concentração de $0,06 \%$ do glifosato, é o melhor método de detecção de semente de soja geneticamente modificada tolerante ao glifosato.

2. As maiores taxas de hibridação natural $(1,27 \%$ em Florestal, 0,25\% em Viçosa) ocorrem a 0,5 m de distância entre doador e receptor de pólen.

3. A taxa de fecundação cruzada aproximou-se de zero às distâncias de 2,26 e 1,16 m da fonte, para Florestal e Viçosa, respectivamente.

\section{Agradecimentos}

Ao CNPq, por concessão de bolsa; à Cooperativa Central de Pesquisa Agrícola (Coodetec), pelo fornecimento das cultivares.

\section{Referências}

ABUD, S.; SOUZA, I.M.; MOREIRA, C.T.; ANDRADE, S.R.M.; ULBRICH, A.V.; VIANNA, GR.; RECH, E.L.; ARAGÃO, F.J.L. Dispersão de pólen em soja transgênica na região do Cerrado. Pesquisa Agropecuária Brasileira, v.38, p.1229-1235, 2003.
AHRENT, D.K.; CAVINESS, C.E. Natural cross-pollination of twelve soybean cultivars in Arkansas. Crop Science, v.34, p.376-378, 1994.

AMARANTE JÚNIOR, O.P.; SANTOS, T.C.R.; BRITO, N.M.; RIBEIRO, M.L. Glifosato: propriedades, toxicidade, usos e legislação. Química Nova, v.25, p.589-593, 2002b.

AMARANTE JÚNIOR, O.P.; SANTOS, T.C.R.; BRITO, N.M.; RIBEIRO, M.L. Métodos de extração e determinação do herbicida glifosato: breve revisão. Química Nova, v.25, p.420-428, 2002a.

BEVILAQUA, G.A.P.; BONATO, E.R.; ROMAN, E.S. Identificação de soja tolerante a glyphosate através do teste de germinação. Revista Brasileira de Herbicidas, v.1, p.261-265, 2000.

BOERMA, H.R.; MORADSHAHI, A. Pollen movement within and between rows to male-sterile soybeans. Crop Science, v.15, p.858861, 1975.

BRASIL. Ministério da Agricultura e Reforma Agrária. Regras para análise de sementes. Brasília: SNDA/DNDV/CLAV, 1992. 365p.

CAVINESS, C.E. Estimates of natural cross-pollination in 'Jackson' soybeans in Arkansas. Crop Science, v.6, p.211-212, 1966.

CONAB. Sexto levantamento da safra agrícola $2005 / 06$. Disponível: <http://www.conab.gov.br>. Acesso em: 16 maio 2006.

CUNHA, C.S.M.; TILLMANN, M.A.A.; VILLELA, F.A.; DODE, L.B.; BALERINI, F. Comparação de métodos na detecção de sementes de soja geneticamente modificada resistente ao glifosato. Revista Brasileira de Sementes, v.27, p.167-175, 2005.

CUTLER, G.H. A simple method for making soybean hybrids. Journal of the American Society of Agronomy, v.26, p.252-254, 1934.

FUNGUETTO, C.I.; TILLMANN, M.A.A.; VILLELA, F.A.; DODE, L.B. Detecção de sementes de soja geneticamente modificada tolerante ao herbicida glifosato. Revista Brasileira de Sementes, v.26, p.130-138, 2004.

GARBER, R.J.; ODLAND, T.E. Natural crossings in soybeans. American Society of Agronomy, v.18, p.967-970, 1926.

GOGGI, A.S.; STAHR, M.G. Roundup ${ }^{\mathrm{TM}}$ pre-emergence treatment to determine the presence of the Roundup Ready ${ }^{\mathrm{TM}}$ gene in soybean seed: a laboratory test. Seed Technology, v.19, p.99-102, 1997.

JAMES C. Executive summary of global status of commercialized biotech/GM crops: 2005. Ithaca: ISAAA, 2005. 1v. (ISAAA briefs, 34).

JONES, D.F.; HAYES, H.K. The purification of soybean varieties. Agricultural Experiment Station, v.5, p.348-353, 1916.

KLEBA, J.B. Riscos e benefícios de plantas transgênicas resistentes a herbicidas: o caso da soja RR da Monsanto. Cadernos de Ciência \& Tecnologia, v.15, p.9-42, 1998.

KRUSE, N.D.; TREZZI, M.M.; VIDAL, R.A. Herbicidas inibidores da EPSPS: revisão de literatura. Revista Brasileira de Herbicidas, v.1, p.139-146, 2000.

MENEZES, S.M.; TILLMANN, M.A.A.; DODE, L.B.; VILLELA, F.A. Detecção de soja geneticamente modificada tolerante ao glifosato por métodos baseados na atividade de enzimas. Revista Brasileira de Sementes, v.26, p.150-155, 2004.

MIRANDA, D.M.; TILLMANN, M.A.A.; BALERINI, F.; VILLELA, F.A. Bioensaios na detecção e quantificação de 
sementes de soja geneticamente modificada resistente ao glifosato. Revista Brasileira de Sementes, v.27, p.93-103, 2005.

MIYASAKA, S. Contribuição para o melhoramento da soja no Estado de São Paulo. 49p. 1958. (Doutorado) - Universidade de São Paulo, Piracicaba.

NAKAGAWA, J. Testes de vigor baseados na avaliação das plântulas. In: VIEIRA, R.D.; CARVALHO, N.M. (Ed.). Testes de vigor em sementes. Jaboticabal: FUNEP, 1994. p.49-85.

PADGETTE, R.; KOLACZ, K.H.; DELANNAY, X.; RE, D.B.; LAVALLÉE, B.J.; TINIUS, C.N.; RHODES, W.K.; OTERO, Y.I.; BARRY, G.F.; EICHHOLTZ, D.A.; PESCHKE, V.M.; NIDA, D.L.; TAYLOR, N.B.; KISHORE, G.M. Development, identification and characterization of a glyphosate-tolerant soybean line. Crop Science, v.35, p.1451-1461, 1995.

PROBST, A.H. Soybean breeding in Indiana. Indiana: Purdue University, 1991. 16p.

RAMALHO, M.A.P.; SANTOS, J.B.; PINTO, C.A.B.P. Genética na Agropecuária. Lavras: Editora UFLA, 200. 472p.

RAY, J.D.; KILEN, T.C.; ABEL, C.A.; PARIS, R.L. Soybean natural cross-pollination rates under field conditions. Environmental Biosafety Research, v.2, p.133-138, 2003.

RUBIS, D.D. Breeding insect-pollinated crops. Arkansas Agricultural Extension Service, v.127, p.19-24, 1970.

SEDIYAMA, T.; CARDOSO, A.A.; VIEIRA, C.; ANDRADE, D. Taxa de hibridação natural na soja, em Viçosa e em Capinópolis, Minas Gerais. Revista Ceres, v.17, p.329-331, 1970.
SHAH, D.M.; HORSCH, R.B.; KLEE, H.J.; KISHORE, G.M.; WINTER, J.A.; TUMER, N.E.; HIRONAKA, C.M.; SANDERS, P.R.; GASSER, C.S.; AYKENT, S.; SIEGEL, N.R.; ROGERS, S.G.; FRALEY, R.T. Engineering herbicide tolerance in transgenic plants. Science, v.233, p.478-481, 1986.

SIMGE - SISTEMA DE METEOROLOGIA E RECURSOS HÍDRICOS DE MINAS GERAIS. Mapas mensais - 2004, 2005. Disponível em: <http://www.simge.mg.gov.br/>. Acesso em: 16 abr. 2007.

SIQUEIRA, J.O.; TRANNIN, I.C.B.; RAMALHO, M.A.P.; FONTES, E.M.G. Interferências no agrossistema e riscos ambientais de culturas transgênicas tolerantes a herbicidas e protegidas contra insetos. Cadernos de Ciência \& Tecnologia, v.21, p.11-81, 2004.

TILLMANN, M.A.A.; WEST, S. Identification of genetically modified soybean seeds resistant to glyphosate. Scientia Agricola, v.61, p.336-341, 2004.

TORRES, A.C.; NASCIMENTO, W.M.; PAIVA, S.A.V.; ARAGÃO, F.A.S. Bioassay for detection of transgenic soybean seeds tolerant to glyphosate. Pesquisa Agropecuária Brasileira, v.38, p.10531057, 2003.

VERNETTI, F.J.; BONATO, E.R.; TEREZAWA, F.; GASTAL, M.F.C. Observações sobre a taxa de cruzamentos naturais em soja em Pelotas e Sertão, RS e Ponta Grossa, PR. Ciência e Cultura, v.1, p.36-41, 1972.

WOODWORTH, C.M. The extent of natural cross-pollination in soybeans. American Society of Agronomy, v.14, p.278-283, 1922.

Recebido em 10 de novembro de 2006 e aprovado em 20 de junho de 2007 